\title{
Methodological aspects of evaluating the effectiveness of using local energy systems with renewable sources
}

\author{
Sergij Dudnikov ${ }^{1}$, Oleksandr Miroshnyk ${ }^{1}$, Stepan Kovalyshyn ${ }^{2}$, Vadym Ptashnyk $^{2}$ and \\ Krzysztof Mudryk ${ }^{3}$ \\ ${ }^{1}$ Kharkiv Petro Vasylenko National Technical University of Agriculture, Institute of Energy and \\ Computer Technologies, 61002 Kharkiv, Ukraine \\ ${ }^{2}$ Lviv National Agrarian University, Faculty of Mechanics and Power Engineering, 80381 Lviv, \\ Ukraine \\ ${ }^{3}$ Faculty of Production and Power Engineering, University of Agriculture in Krakow, Str. Balicka \\ 116b, 30-149 Krakow, Poland
}

\begin{abstract}
A method is presented for justifying the construction of a mathematical model of the process of supplying consumers from local sources, taking into account deterministic input information. The target function of the mathematical model is to minimize financial investments in the construction and operation of the local energy supply system using renewable energy sources. Presented activities are aimed at assessing the efficiency of use of fuel and energy resources by local power supply systems, determining the conditions for a positive economic effect, substantiating the composition and main technical parameters of power plants and devices of the local power supply system. At the same time, the conditions of competitiveness of the local power supply system relative to the centralized one should be observed. Sources of local power supply systems should be built on the basis of biogas plants that are capable of producing biogas with long-term storage in gas storages and at the same time are energy storage batteries for other renewable sources. The presented analysis of the energy balance of a biogas plant, taking into account the synergistic effects of interaction between centralized and local energy systems, will make it possible to make optimal decisions for creating a bioenergy complex.
\end{abstract}

\section{Introduction}

Today, there are objections and opposing judgments on the effective use of renewable energy sources (RES), and the main one is the high cost of energy that the consumer receives from the local energy supply system using LSRES compared to the energy resources of the centralized system (CS), and also The emergence of conditions of uncertainty regarding the justification of the limits of the costs of its implementation, in which the consumer will have a positive economic effect. The above factors restrain the consumers' desire to build LSRES in both the stand-alone operation mode and in the combined power supply system (CPSS) with CS sources. 
Prospects for the use of energy resources from alternative sources are due to the forecasted growth in the price of all fossil fuels for the period up to 2030 in the countries of Europe and the Russian Federation [1], with a subsequent tendency to increase. The dynamics of the growth of prices for energy resources for different countries of Europe [2, 3] can occur with temporary fluctuations, which are caused by the demand, the exhaustion of readily accessible organic fuel deposits, the environmental state of the environment and other factors, including political ones. The solution of this problem on a global scale is connected with the search and use of new technologies for the transformation of various types of energy, including alternative ones [4-11].

In the construction of the CPSS, the volume of the cost limits $\left(d B_{i}\right)$ for the $i$-th year for its construction and operation, under which the consumer will have a positive economic effect, is reasonable to justify, taking into account DSTU 3886-99 "Energy Saving", where the efficiency criterion is the positive economic effect of Realization of energy-saving measures (ESM) for the settlement period $t$. The cost estimate of ESM is determined by the dependence [12]:

$$
\Delta D_{t}=E_{s y}-E_{c y}=E_{s y}-\left(\Delta E_{s y}+\Delta E_{l y}\right)=>\max
$$

where $\Delta D_{t}$ - the value of the differential economic indicator (DEI) from the introduction of CPSS, the volume of which is based on the amount of cash receipts from the implementation of energy-saving measures for the $t$-th period, \$;

$E_{s y}, E_{c y}, \Delta E_{s y}, \Delta E_{l y}$ - Respectively, the annual costs for the purchase of energy carriers from: CS; CPSS; CS as part of CPSS; LSRES as part of the CPSS, \$;

In the development of CPSS, it is recommended that several key measures be taken into account, the main ones of which we attribute [12]:

1. determination at the first stage of development of the marginal cost limit for the implementation of LSRES, in which the consumer will have a cash income;

2. technical, technological and other measures to reduce the cost of implementing LSRES.

Climatic and geographical conditions make it possible to widely use alternative types of energy from renewable sources throughout Ukraine and have positive indicators of energy saving projects.

According to [12] the CSES of AIC consumers, which includes CS and LSRES, for most regions of Ukraine is advisable to create on the basis of a biogas plant (BGP). BGP can be used as a battery for other sources of alternative energy, and produced biogas is capable of long-term accumulation and can be used in terms that are beneficial to the consumer.

The aim of research is to improve the structure of the CSES of consumers of the agroindustrial complex on the basis of assessing the economic effect of the use of AES and energy balance data of BGP.

\section{Experimental}

The use of AES by AIC consumers depends on a large number of factors, some of which can be considered constant, while others may have a probabilistic nature. In addition, it should be borne in mind that the creation of the LSRES system requires significant capital investments, which must be returned for the period stipulated by the investor.

According to [13], the main criterion for assessing the effectiveness of an investment project, without taking into account the discount rate, is the value of the current annual income $P$ : 


$$
P=I-E,
$$

where $I-$ the annual revenue from the sale of energy, \$;

$E$ - annual estimated costs, \$.

Equating the positive value of DEI to income, $\Delta D_{t} \approx I$, then the period for the return of investment $\left(P_{p}\right)$ is determined by the formula taking into account [13]:

$$
P_{p}=\frac{E}{\Delta D_{t}}=\frac{\tau \cdot K+C_{o}}{\Delta D_{t}}
$$

where $K$ - capital investments for the creation of CPSS, \$;

$\tau$ - constant discount rate, r.u.;

$C_{o}$ - annual recurrent costs, $\$$.

To implement CPSS or its individual components, annual capital investments should not exceed the values:

$$
K<\frac{P_{p} \cdot \Delta D_{t}-C_{o}}{\tau} .
$$

Taking into account $(2,3)$, the annual calculated expenses should be less than the following:

$$
\begin{array} { l }
\left.\begin{array}{l}
E<\Delta D_{t}-P_{p} \\
\Delta D_{t}=E_{s y}-E_{c y}=E_{s y}-\left(\Delta E_{s y}+\Delta E_{l y}\right)= \\
{ ={ = [\begin{array}{cccccc}
\text { Energy } & \text { elektric } & \text { heat } & & \text { fuel } & \text { ferilizer } \\
\cline { 2 - 3 }
\end{array}} & & & & \\
\text { Winter } & k_{11} q W & k_{12} b Q & & k_{13} a V & k_{14} d G \\
\text { Spring } & k_{11} q W & k_{12} b Q & & k_{13} a V & k_{14} d G \\
\text { Summer } & k_{11} q W & k_{12} b Q & & k_{13} a V & k_{14} d G \\
\text { Autumn } & k_{11} q W & k_{12} b Q & & k_{13} a V & k_{14} d G
\end{array}\right] } \\
{-\left(\left[\begin{array}{cccccc}
\text { Energy } & \text { elektric } & \text { heat } & & \text { fuel ferilizer } \\
\cline { 2 - 5 } \text { Season } & & & & \\
\text { Winter } & z_{11} q W & z_{12} b Q & & z_{13} a V & z_{14} d G \\
\text { Spring } & z_{11} q W & z_{12} b Q & z_{13} a V & z_{14} d G \\
\text { Summer } & z_{11} q W & z_{12} b Q & z_{13} a V & z_{14} d G \\
\text { Autumn } & z_{11} q W & z_{12} b Q & z_{13} a V & z_{14} d G
\end{array}\right]\right.}
\end{array}
$$

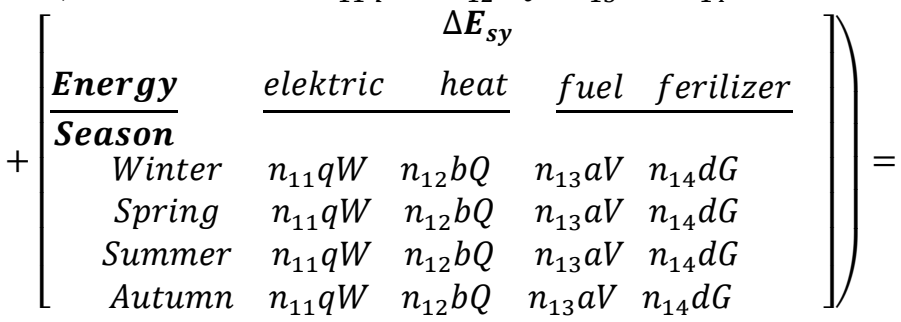

$$
\begin{aligned}
& =\Delta W_{a}(\Delta q)+\Delta Q_{a}(\Delta b)+\Delta V_{a}(\Delta a)+\Delta G(\Delta d) \text {, }
\end{aligned}
$$


where $k_{i j}, z_{i j}, z_{i j}$ - accordingly, the coefficients that characterize the degree of use by the consumer of the $j$-type energy $\left(W_{i}, Q_{i}, V_{i}, G_{i}\right)$ In the $i$-th season, relative to the annual volume of consumed $j$-type energy $(W, Q, V, G)$ from CS, CS to CPSS, LSRES to CPSS, p.y.;

$\Delta W_{a}, \Delta Q_{a}, \Delta V_{a}, \Delta G_{a}$ - respectively the volumes of electricity, heat, fuel for vehicles and fertilizers from LSRES, kWh, Gcal, t;

$\Delta q, \Delta b, \Delta a, \Delta d$ - respectively, the difference in the cost of electricity, heat, fuel, fertilizer, the volumes of which are bought from $\operatorname{CS}(q, b, a, d)$, and the cost of the same types of energy generated by LSRES $\left(q_{a}, b_{a}, a_{a}, d_{a}\right): \Delta q=q-q_{a}, \Delta b=b-b_{a}, \Delta a=a-a_{a}, \Delta d=d-$ $d_{a}, \$ / \mathrm{kWh}, \$ /$ Gcal, $\$ / \mathrm{t}, \$ / \mathrm{m}^{3}$

$q_{a}, b_{a}, a_{a}, d_{a}$ - respectively the tariff value of electricity, heat, fuel for vehicles and fertilizers from LSRES, \$/kWh, \$/Gcal, \$/t;

$q, b, a, d$ - respectively, the tariff value of electric, thermal energy, fuel for vehicles and fertilizer from the CA, $\$ / \mathrm{kWh}, \$ / \mathrm{Gcal}, \$ / \mathrm{t}$.

In expanded form, the dependence (1) can be represented in the form of the matrix equation (6). According to the analysis of equation (6), the value of the annual use efficiency of CPSS is functionally dependent on the volume of production of various types of energy by the local system and the difference in the monetary costs of obtaining the corresponding types of energy from centralized and local systems.

Depending on the factors that generate inflation for energy carriers CS, the value of DEI may change towards positive growth, or a negative decrease. Under the expected inflation, DEI calculation requires adjustments, for example, by using coefficients that are calculated by theories of economic science.

In order to investigate possible alternative solutions for determining the annual monetary effect in both real and predicted time for AIC consumers using AES in the combined power supply system, the represented matrix equation (6) has a number of solutions for the year $t$ with a positive or negative result.

From the analysis (3-6) it follows that with the help of DEI, it is possible to eliminate or significantly weaken the uncertainty in justifying the allowable costs.

It is worth noting that the above parameters (6) are variable quantities having either a continuous probabilistic character, for example, the consumption of electrical energy (if there are no short-term interruptions in electricity supply), or discrete, for example: The introduction of fertilizers into the soil, which is carried out mainly in the autumn season, or the use of thermal energy - only mainly in the heating season. This greatly complicates the issue of determining the monetary benefit to the consumer and the share of LSES energy carriers in CPSS, the volumes of which depend on local climatic and geographical conditions and the mass of waste of vegetable and animal origin. To eliminate the conditions of uncertainty, we equate the value of $\Delta D_{t}$ (1) to the cash cost limit $d B_{i}$, the volumes of which, depending on the cost of energy produced by the local energy system, can have both positive and negative values. Consider three possible cases:

$d B_{i}<0$ - the consumer should abandon the CPSS construction, or take the necessary measures to reduce the cost of produced energy;

$d B_{i}=0$ - energy costs from LSRES will equal the purchase of energy from the CS. No funds are available to repay the loan. In the absence of conditions for subsidies from the state, the consumer should abandon CPSS construction;

$d B_{i}>0$ - the consumer will profit from the introduction of CPSS. The cost of generating energy from LSRES will be less than the purchase of energy from the CS. The introduction of CPSS is proposed when the consumer has a positive economic effect, that is, if the following conditions are met:

$$
d B_{i}>C_{i}
$$


where $C_{i}-$ is the cost of implementing and using CPSS.

The ratio between $d B_{i}$ and $C_{i}$ is:

$$
C_{i}=d B_{i}-P_{i}
$$

where $P_{i}-$ is the net profit from the introduction of CPSS for the $i$-th year, $\$$.

The economic feasibility of implementing CPSS is characterized by the definition of the allowable cost limit $\left(d B_{i}\right)$ for its construction and operation, in which the consumer will have a net positive economic effect Eei for the $i$-th year, taking into account $[14,15]$ :

$$
E e_{i}=d B_{i}-C_{i}
$$

where $C_{i}-$ is the cost of implementing and using CPSS for the i-th year, $\$$ :

$$
C_{i}=E_{i}+r K_{i}
$$

$E_{i}$ - the cost estimate of depreciation charges for renovation, operational and other costs in LSRES for the $i$-th year, $\$$;

$\mathrm{r}$ - bank interest rate, r.u.;

$K_{i}$ - capital investments in the LSRES project for the $i$-th year, \$.

To make a decision to determine the cost of building CPSS, it is necessary to construct a nomogram of cost boundary changes from $d B_{i}=0$ to $d B_{i}=$ max, depending on the cost and volumes of produced and used energy types LSRES. In the future, with the known volumes of the cost of produced energy, the local system, according to the nomogram, establishes the limits of costs.

At the same time, in order to ensure that the consumer will have money profit from the use of LSRES, the cost limit should not be less than the "zero" level.

To solve the problem posed by studying the changes $d B_{i}$ from input values in dynamics, we use the graph-analytical method of calculation in accordance with the developed program, the generalized block diagram of the algorithm is shown in Fig. 1 and adapted for the processing of computer data in the software package MATLAB version 6.5. Also, the use of this program will allow to identify other interconnected economic indicators (volumes of capital investments, terms of return of monetary investments, etc.).

The algorithm of the program consists of three main stages:

1. Data input, characterizing: the amount of consumed period of the year of different types of energy from LSRES ( $\left.W_{a}, Q_{a}, V_{a}, G_{a}\right)$; Tariffs for various types of energy CS $(a, b, q$, $d)$; The cost of various types of energy $\operatorname{LSRES}\left(q_{a}, b_{a}, a_{a}, d_{a}\right)$.

2. Justification of cost limits $d B_{i}$, depending on the share of energy use and energy tariffs for LSRES.

3. Calculation of basic technical parameters of LSRES devices.

To verify the developed program (Fig. 1) we will use the factual information of the private agricultural enterprise "Tavolzhanskoe" of the Dvurechansky district of the Kharkov region. According to the reporting data on energy carriers and information, which is concentrated in the company's energy passport, we establish that the agricultural consumer purchased energy from the CS for the period 2016 at tariffs: diesel fuel $a=889 \$ / \mathrm{t}$, thermal energy — $b=48 \$ / \mathrm{Gcal}$ or $(11,5 \$ / \mathrm{Gj})$, electric energy $q=0,07 \$ / \mathrm{kWh}$.

The range of the change in the cost price of the produced energy by the local system will be taken as: diesel fuel $a_{a}=[0-1400] \$ / t$, thermal energy $b_{a}=[0-100] \$ / G c a l$. Fertilizers at the enterprise "Tavolzhanskoe" are planned to be introduced to areas where potatoes are grown. The recommended volume of application of liquid high-quality organic fertilizers from BGP, in which the potato has the highest yield, is $H-5 \mathrm{t} / \mathrm{ha}$. Average 
potato yield in Ukraine $Y_{c}-16 \mathrm{t} / \mathrm{ha}$. Complex mineral nitrogen-phosphate-potassium fertilizers, which were purchased at a price of $P f-500 \$ / \mathrm{t}$ at a consumption of $250 \mathrm{~kg} / \mathrm{ha}$, are planned to be replaced by high-quality fertilizers from BGP.

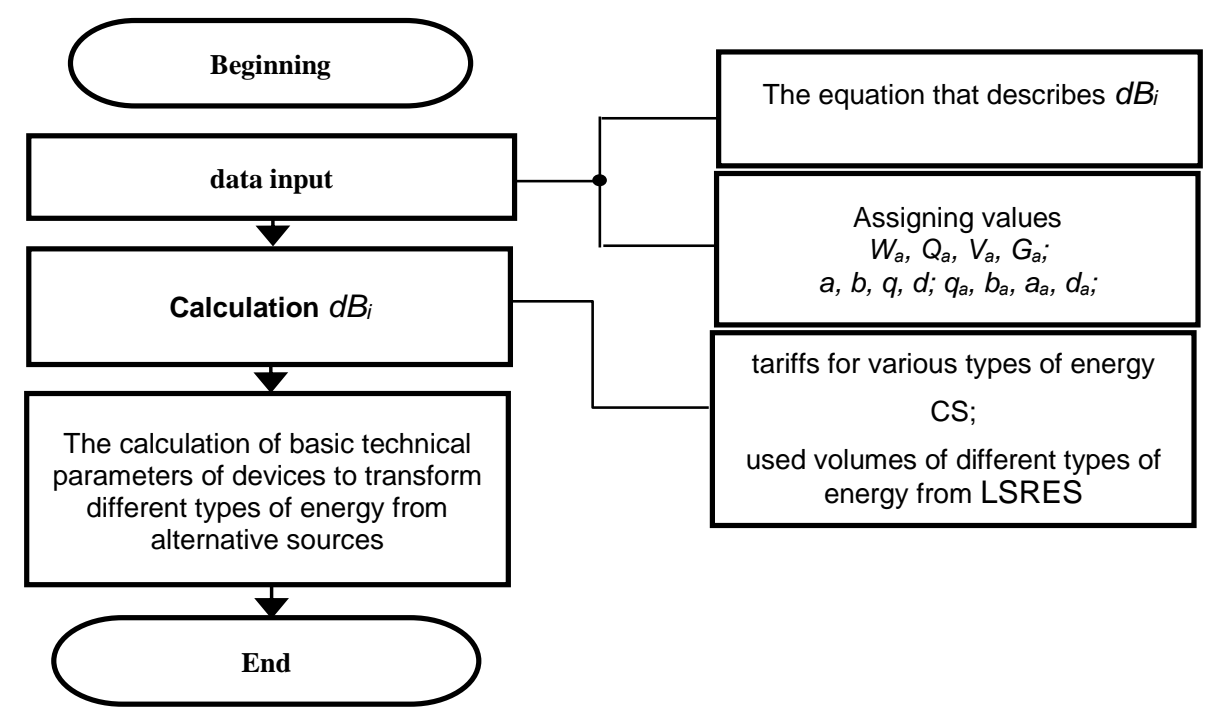

Fig. 1. Structural diagram of the algorithm for calculating the change in the cost limits $d B_{i}$.

Taking into account the manure manure waste, the volume of the BGP reactor is $V_{B G P}=200 \mathrm{~m}^{3}$, which theoretically will make it possible to produce: thermal energy $Q_{a}=388,8 \mathrm{Gj} /$ year; fuel for vehicles and agricultural machinery $N_{a}=23,8 \mathrm{t} /$ year; revenues related to the reduction of monetary investments for the purchase of mineral fertilizers for the introduction of arable land for potatoes into the appropriate area: $G_{a}=I_{f}=4500$ \$/year (Suppose that this quantity is constant).

Taking into account (6) for the proposed CPSS, the $d B_{i}$ index for the $i$-th year will be:

$$
d B_{i}=W_{a i}\left(\Delta q_{i}\right)+Q_{a i}\left(\Delta b_{i}\right)+V_{a i}\left(\Delta a_{i}\right)+I_{f i}+I_{s i}
$$

To simplify the calculations, suppose that the income from the use of energy will be constant, and the total amount of additional revenues from the use of innovative technologies will not be taken into account.

To solve the problem in dynamics, we use the developed program (11), the generalized structural scheme of the algorithm is shown in Fig. 1 and is adapted for computer data processing in the mathematical software package MATLAB version 6.5. Based on the results of the calculation, the area of eligible costs $d B$ is determined, which correspond to a set of possible estimates of the economic effect from the introduction of CPSS (Fig. 2).

When designing CPSS, it is advisable to consider the variants when $d B_{i}>0$, which subsequently, according to (9), will allow us to obtain from its use a positive economic effect for the year $i$. We will postpone on the nomogram the prime cost of various types of produced energy LSRES, for example $b_{a}=40 \$ / \mathrm{GJ}, a_{a}=800 \$ / \mathrm{t}$. Their intersection will be denoted by point 1 (Fig. 2). The next step is to establish the permissible value of annual costs (point 2) for the implementation of CPSS, which is predicted on the basis of BGP with a reactor volume of $200 \mathrm{~m} 3$ (taken from the preliminary processing of computer data the third stage of the algorithm block diagram, Fig. 1 .): $\mathrm{dBi} \approx 16000 \$ /$ year.

Limit of admissible costs $\mathrm{Cv}$ in view of service life BGP Po (20 years):

$$
C_{V}=d B \cdot P_{0}=16000 \cdot 20=320000 \$ .
$$




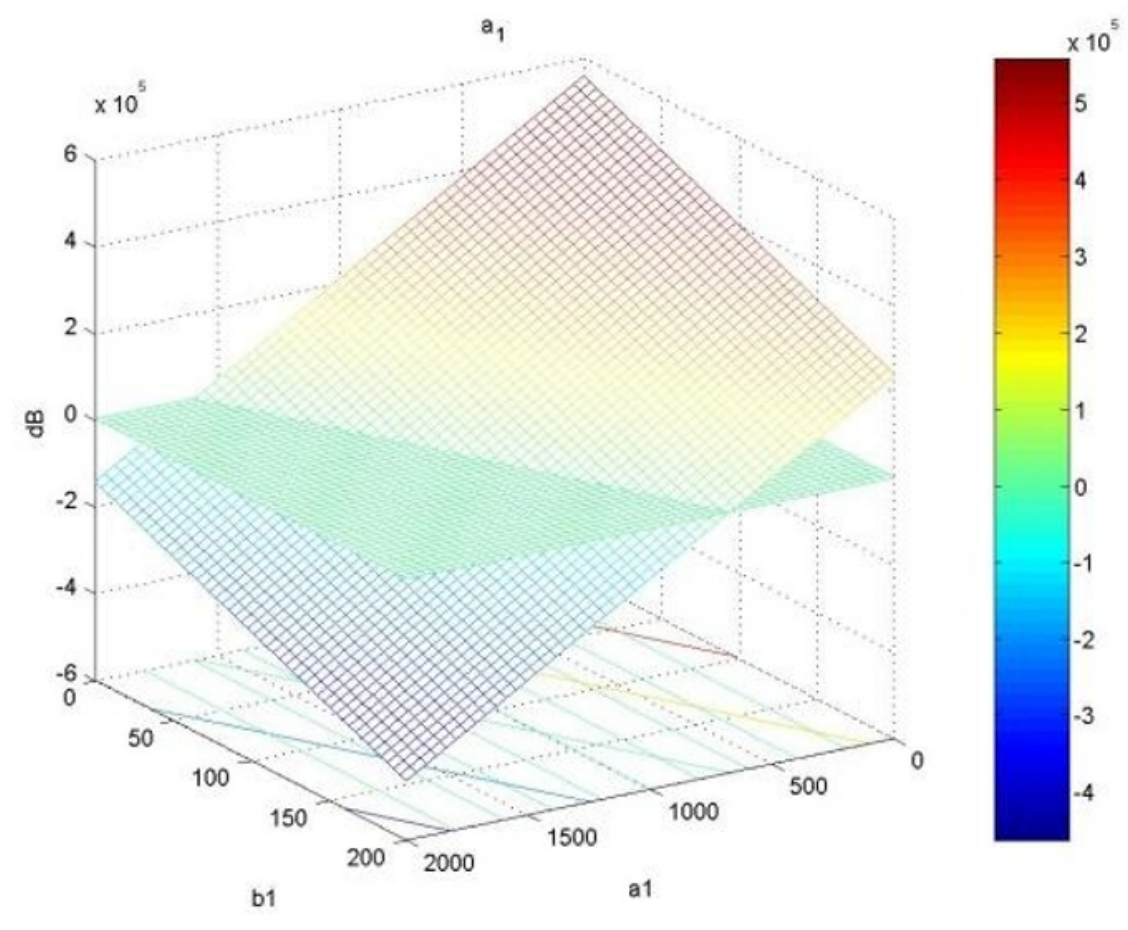

Fig. 2 Nomogram of annual cost limits $(d B)$, under which the consumer will have a positive economic effect from the introduction CPSS.

Capital costs excluding the discount factor for construction BGP:

$$
K_{B G R}=B_{B G R} \cdot V_{B G R}=500 \cdot 200=100000 \$ .
$$

where $B_{B G P}$ - average statistical data on costs of purchase BGP [4], $B_{B G P}=500 \$ / \mathrm{m}^{3}$.

In doing so, conditions for a positive economic effect are fulfilled (7):

$$
d B_{i} \cdot(16000)>C_{i} \cdot(5000),
$$

where $C_{i}=\mathrm{K}_{\mathrm{BGR}} / \mathrm{P}_{0}=100000 / 20=5000 \$$.

Thus, having a positive evaluation of the use of AES and the power of devices for conversion of AES (WPS, STC, BGP, etc.), We pass to the second stage of the solution of the problem - Organizational, technological and technical directions of solving problems on reducing the influence of internal factors on the amount of cash costs to the level of the established limit. Organizational and technological tasks include: conducting energy audit; analysis of the created energy balance by determining the types and volumes of energy produced, including losses and costs at each stage of its transformation; harmonization of the technological process of production and consumption of energy, taking into account the willingness of the consumer to take energy from alternative sources at the time of its appearance.

Based on the results of the energy audit conducted by BGP, flows of various types of energy are systematized, losses and expenses are determined, the volumes of which are presented in Table 1. 
Table 1. BSU energy balance.

\begin{tabular}{|c|c|c|c|c|c|c|c|c|c|}
\hline \multirow{2}{*}{$\begin{array}{l}\text { № } \\
\mathbf{i} / \mathbf{o}\end{array}$} & \multirow{2}{*}{ Types of energies } & \multicolumn{2}{|c|}{ Winter } & \multicolumn{2}{|r|}{ Spring } & \multicolumn{2}{|c|}{ Summer } & \multicolumn{2}{|c|}{ Autumn } \\
\hline & & & $M W h / m^{3}$ & $\%$ & $M W h / m^{3}$ & $\%$ & $M W h / m^{3}$ & $\%$ & $M W h / m^{3}$ \\
\hline \multicolumn{10}{|c|}{ Output power } \\
\hline \begin{tabular}{|l|}
1. \\
\end{tabular} & Energy fertilizers & 82,2 & 3,86 & 82,5 & \begin{tabular}{|l|l|}
5,94 \\
\end{tabular} & 82,7 & 3,94 & 82,39 & 3,89 \\
\hline 2. & Energy biogas & 15,3 & 0,71 & 15,1 & 0,72 & 15,2 & 0,72 & 15,2 & 0,72 \\
\hline 3. & $\begin{array}{c}\text { Thermal energy contained } \\
\text { in fertilizer }\end{array}$ & 2,5 & 0,12 & 2,4 & 0,11 & 2,1 & 0,1 & 2,41 & 0,11 \\
\hline & Total, \% & 100 & & 100 & & 100 & & 100 & \\
\hline \multicolumn{10}{|c|}{ Input power } \\
\hline 4. & $\begin{array}{c}\text { The energy of organic } \\
\text { waste humidity }(94-96) \%\end{array}$ & 58,6 & 2,75 & 58,7 & \begin{tabular}{l|l}
7,87
\end{tabular} & 58,86 & 2,81 & 58,8 & 2,78 \\
\hline 5. & $\begin{array}{c}\text { Energy for heating the } \\
\text { organic waste to a } \\
\text { predetermined temperature } \\
\text { after loading }\end{array}$ & 2,5 & 0,12 & 2,4 & 0,11 & 2,14 & 0,1 & 2,47 & 0,11 \\
\hline 6. & $\begin{array}{l}\text { Energy to maintain the } \\
\text { specified temperature in } \\
\text { the BGP reactor }\end{array}$ & 5,3 & 0,23 & 3,2 & 0,15 & 1,67 & 0,08 & 3,23 & 0,15 \\
\hline 7. & $\begin{array}{l}\text { Electricity for mixing, } \\
\text { grinding, loading and } \\
\text { unloading of organic } \\
\text { matter, filling of water } \\
\text { heat accumulators }\end{array}$ & 4,7 & 0,22 & 4,65 & 0,22 & 4,66 & 0,22 & 4,7 & 0,22 \\
\hline 8. & $\begin{array}{l}\text { Energy for compressor } \\
\text { operation when filling } \\
\text { biogas in cylinders and } \\
\text { supplying an electric } \\
\text { generator to the ICE, as } \\
\text { well as cleaning biogas } \\
\text { from } \mathrm{CO}_{2} \text { and } \mathrm{H}_{2} \mathrm{O} \\
\end{array}$ & 0,06 & 0,003 & 0,06 & 0,003 & 0,06 & 0,003 & 0,06 & 0,003 \\
\hline 9. & Energy losses in pipelines & 0,06 & 0,003 & $0,05 \mid$ & 0,002 & 0,04 & 0,001 & 0,05 & 0,002 \\
\hline 10. & $\begin{array}{l}\text { Energy received by } \\
\text { fertilizer due to the action } \\
\text { methane-forming bacteria }\end{array}$ & 23,6 & 1,11 & 23,8 & 1,14 & 23,9 & 1,14 & 23,5 & 1,11 \\
\hline 11. & $\begin{array}{c}\text { The energy of biogas } \\
\text { obtained as a result of the } \\
\text { action of methane-forming } \\
\text { bacteria }\end{array}$ & 15,2 & 0,71 & 15,1 & 0,72 & 15,2 & 0,72 & 15,2 & 0,72 \\
\hline & $\begin{array}{l}\text { tal in relation to the initial } \\
\text { energy, } \%\end{array}$ & 110 & & 108 & & 106,5 & & 108 & \\
\hline \multicolumn{10}{|c|}{ Trading biogas energy } \\
\hline 12. & $\begin{array}{c}\% \text { of the amount of total } \\
\text { energy }\end{array}$ & 2,84 & \multirow{2}{*}{0,13} & 4,78 & \multirow{2}{*}{0,23} & 6,66 & \multirow{2}{*}{0,32} & 4,83 & \multirow{2}{*}{0,23} \\
\hline 13. & $\begin{array}{c}\% \text { from the obtained } \\
\text { biogas }\end{array}$ & 19 & & 32 & & 44 & & 32 & \\
\hline
\end{tabular}


Based on the data in Table 1, a diagram is constructed to illustrate changes in the energy balance of BGP (fig. 3).

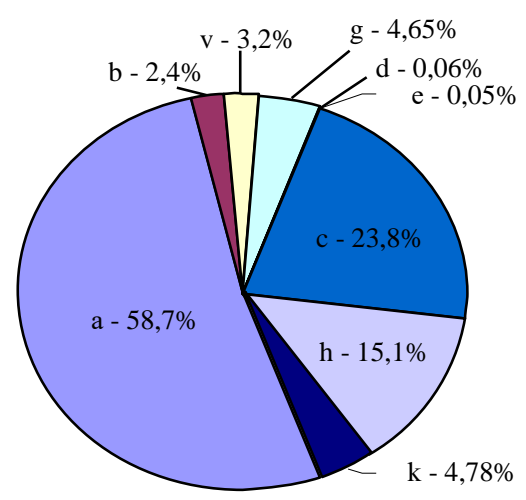

Fig. 3 The diagram of the average annual energy balance of BGP, where the sectors of the circle:

a - percentage of incoming energy of organic waste by humidity $(92 \ldots 96) \%$;

$\mathrm{b}$ - energy consumption for the pre-heating of manure, \%;

$\mathrm{v}$ - energy consumption to maintain the temperature in the BGP reactor, \%;

$\mathrm{g}$ - energy consumption for mixing, grinding, loading and unloading of organic matter, adjustment of moisture content in organic waste to the level (92 ... 96)\%, filling of water heat accumulators, \%; $\mathrm{d}$ - energy consumption for compressor operation when filling biogas in cylinders and supplying biogas to internal combustion engines ICE electric generator, as well as for cleaning biogas from $\mathrm{CO}_{2}$ and $\mathrm{H}_{2} \mathrm{O}, \%$;

$\mathrm{e}-$ loss of energy in pipelines, $\%$;

$\mathrm{c}-$ energy received by fertilizer as a result of processing of organic waste by methane-forming bacteria, \%;

$\mathrm{h}$ - energy in the form of biogas obtained as a result of the action of methane-forming bacteria, \%; $\mathrm{k}$ - volumes of commodity energy of biogas in relation to the total received volumes of biogas energy, $\%$.

For further study, we represent the energy balance of BGP taking into account Table 1 and the diagram in Fig. 3, in the general form:

$$
W_{1}+W_{2}+W_{3}=W_{0}+W_{4}+W_{5}-k W_{5}-W_{6}-W_{k}
$$

where $W_{1}$ - consumed biogas energy, $\mathrm{kWh}$;

$W_{2}$ - the energy received by the consumer of fertilizers of liquid and solid fractions, $\mathrm{kWh}$;

$W_{3}$ - the volumes of thermal energy received by the consumer, $\mathrm{kWh}$;

$W_{0}$ - energy of organic waste, $\mathrm{kWh}$;

$W_{4}$ - energy received by fertilizer due to the action of methane-forming bacteria, $\mathrm{kWh}$;

$W_{5}$ - the energy of biogas formed as a result of the action of methane-forming bacteria, $\mathrm{kWh}$;

$k$ - the coefficient characterizing the share use of biogas for own needs, $k=(0 \ldots 1)$ r.u.;

$W_{6}$ - total losses of thermal energy BGP: in the reactor BGP, pipelines and other devices and structures, $\mathrm{kWh}$;

$W_{\kappa}$ - other $\kappa$-types of energy that the consumer uses for his own needs BGP:

$$
W_{k}=W_{7}+W_{8}+W_{9}+W_{10}
$$

where $W_{7}$ - volumes of energy for initial heating of manure, $\mathrm{kWh}$;

$W_{8}$ - volumes of energy for maintaining the temperature in the reactor BGP, $\mathrm{kWh}$; 
$W_{9}$ - volumes of energy for mixing, grinding, loading and unloading of organic matter, filling of water heat accumulators, $\mathrm{kWh}$;

$W_{10}$ - energy consumption for compressor operation when filling biogas in cylinders and supplying biogas to ICE electric generator, as well as for cleaning biogas from $\mathrm{CO}_{2}$ and $\mathrm{H}_{2} \mathrm{O}$, kWh.

Analysis of energy balance data (15), Table 1 and Fig. 3 shows that:

- the use of BGP allows the consumer to produce high-quality fertilizer and biogas with subsequent conversion into thermal, electrical energy and fuel for vehicles;

- the volumes of commodity biogas received by the consumer, depending on the seasons of the year, are (19 ... 44) \% of the total volumes of biogas produced.

At the same time, the use of WPS and STC energy for power supply of BGP allows to increase up to three times the average annual output of commodity biogas.

Thus, using the energy balance when creating LSRES allows:

- identify the amount of excessive energy costs and develop measures to eliminate them;

- justify the selection of the most economical types of energy produced and the parameters of energy carriers used in technological processes;

- decide on the selection or creation of the most rational energy supply systems for AIC consumers.

According to the BGP energy balance (Table 1, fig. 3), the average annual consumption of biogas volumes for maintaining the BGP temperature regime for most regions of Ukraine is about $70 \%$ of the total volume. It should be borne in mind that the main energy resources of BGP are contained in biomass, and from the biogas energy during the conversion the consumer can receive electricity, heat and fuel for the internal combustion engine, which should be taken into account when creating the CPSS structural diagram.

A feature of this energy balance is the use of wind and solar energy for the production of thermal energy to meet BGP own needs. Thus, the use of the BGP as a battery for energy, the volumes of which come from alternative sources, in the structural and design solution allows to increase the production of commercial biogas up to three times. Produced biogas, capable of long and relatively "cheap" storage, can be used by the consumer at any time that is necessary for him. When constructing such LSRES schemes, conditions are created for increasing the volumes of commodity energy, constant readiness of the consumer to use alternative energy sources and, as a consequence, increasing the efficiency of using AES.

Based on the proposed BGP energy balance (Table 1, diagrams in Figure 3), a CPSS flowchart is developed with predictable rational use of different types of AES, one example of which is presented in Fig. 4.

The cost of generated energy $\mathrm{Cp}$ from LSRES is not constant and depends on the cost of implementation, additional overhead costs and the amount of useful energy used by local devices. The general form of the dependence of these changes can be represented in the form:

$$
C_{p}=\frac{K_{i}}{W_{i U}}
$$

where $K_{i}$ - capital investments in the ICAUD project for the $i$-th year, $\$$; $W_{i U}$ - the amount of energy that the consumer has benefited from from LSRES, for the $i$-th year, kWh.

To determine the actual volumes of the useful energy we use, we introduce the coefficient $K_{d}$, which characterizes the discrepancy between the load curves of agricultural consumers and the availability of energy, the volumes of which are generated by LSRES: 


$$
K_{d}=\frac{W_{t U}}{W_{t P}}
$$

where $W_{t P}$ - respectively, the energy volumes generated by the LSRES during a certain time interval $t, \mathrm{kWh}$.

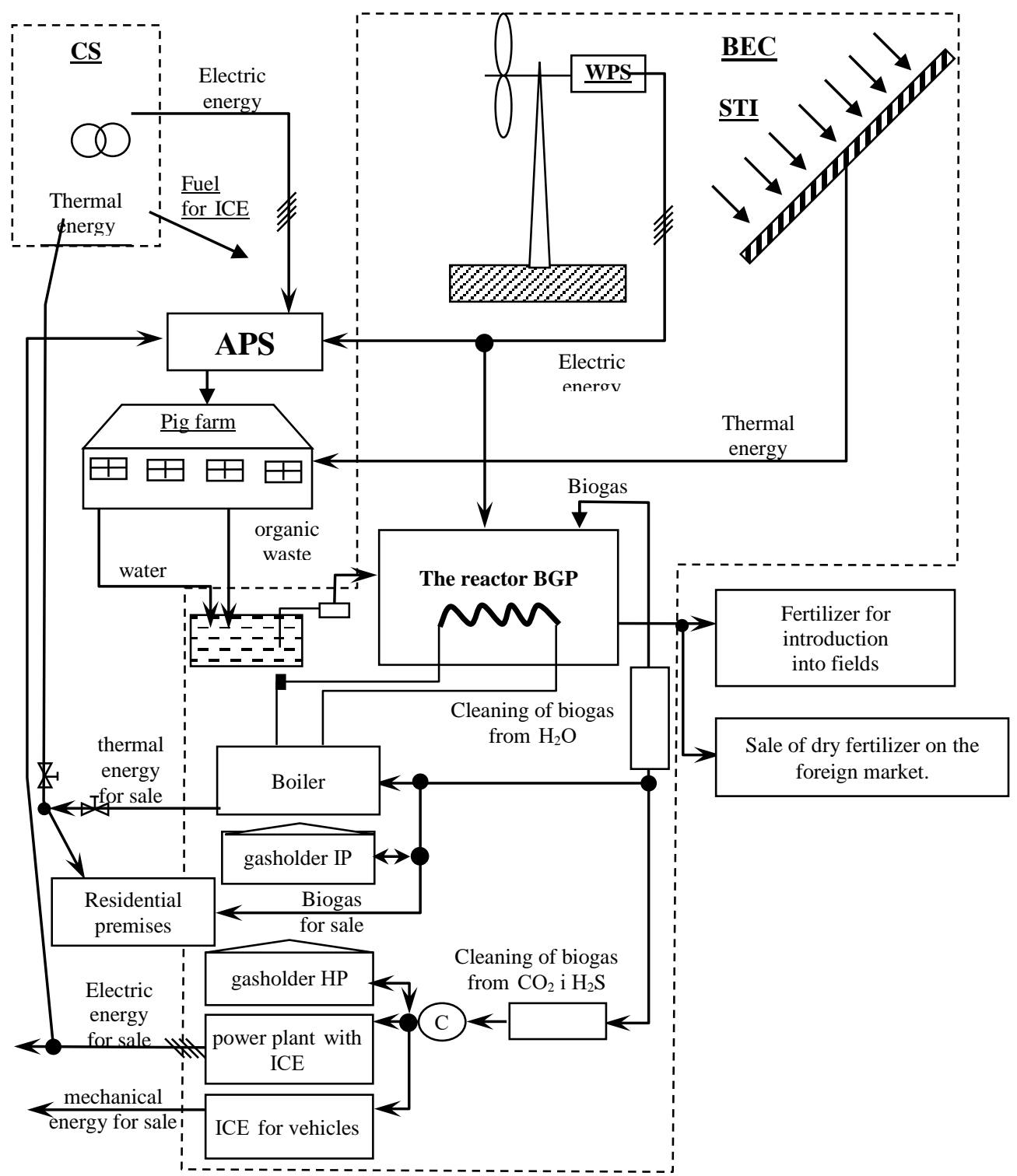

Fig. 4 Block diagram CSES.

The value of $K_{d}$ can be in the range from 0 to $1: 0 \leq K_{d} \leq 1$. When $K_{d}=0$, the consumer does not use the generated energy from LSRES, and vice versa, when $K_{d}=1$, the consumer uses all the volumes of energy produced.

To increase the value of $K_{d}$, it is necessary to reconcile the load curves of the consumer with the volumes of energy input from the LSRES. For example, for WPS it is recommended to use the organic liquid of a BGP reactor as a storage battery. This, in turn, 
will increase the volumes of commodity biogas suitable for long-term storage, which will allow using it at times when it is necessary or beneficial to the consumer.

Therefore, in determining the amount of energy generated by LSRES devices, the $K_{d}$ value must be taken into account. So, for example, when using biogas as a fuel for power generation, the volumes of generated BGP energy taking into account [4] are determined by the formula:

$$
W_{B G P}=\eta \cdot K_{d} \cdot K_{u} \int_{0}^{t} P_{t} d t
$$

where $P_{t}$ - is the power of the power plant at hour $t, \mathrm{\kappa W}$;

$K_{u}$ - coefficient that takes into account the amount of BGP energy used for own use, $0 \leq K_{u} \leq 1$, r.u.;

$\eta$ - the overall Coefficient of efficiency of a BGP, r.u.;

$t$ - time of use of generated energy BGP, h;

The process of energy production on BGP has the following features:

- The possibility of stable production of energy during the day, season, year;

- The possibility of accumulating primary energy, biogas through its accumulation in gasholders, as a result of which the consumer can use the entire amount of energy produced at the time necessary for it. In this case, the value of the coefficient $\mathrm{Kn}$ is equal to or approaches unity.

The proposed LSRES in CPSS includes: a reactor for the fermentation of manure; Storage tank for biogas; A kit for biogas preparation for use in internal combustion engines (ICE), which includes a compressor unit with a set of devices and installations for cleaning biogas from $\mathrm{H}_{2} \mathrm{O}$ and $\mathrm{H}_{2} \mathrm{~S}$; A set of tanks for biogas for ICE; An energy generator based on ICE, WPS, and also STC for maintaining the thermal regime in the reactor and tanks for the preparation of the fermentation mixture. The fertilizer tank from the BGP reactor is equipped with a heat exchanger through which water is supplied to the tank for the preparation of a mixture of organic waste, which reduces energy costs for heating of organic waste.

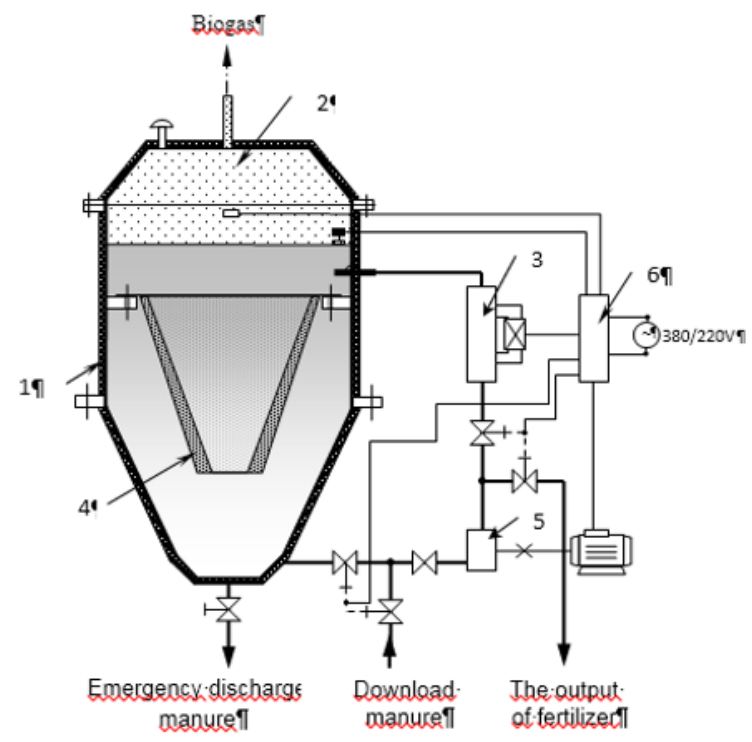

Fig.5. Biogas plant of a small farm: 1 - tank for the fermentation of organic waste; 2 - gasholder; 3 flow induction heater; 4 - nozzle; 5 - fecal pump with a grinder; 6 - automatic control unit. 
Technical measures to reduce the impact of internal factors on the amount of cash costs to the level of the established limit include the development of new and improvement of existing installations and devices for converting energy from alternative sources. The measures taken should ensure the reduction of the cost of the generated types of energy.

As an example, we will present a variant for designing the technical components of the LSRES devices - the construction of a BGP small farm [16, 17] (fig. 5).

The reduction in the cost of the developed BGP is achieved by introducing an induction heater 3 into the heating and mixing system of organic raw materials, which makes it possible to simplify the construction of the methane tank 1 , reduce metal consumption, repair and maintain the main BGP devices without stopping the workflow.

The increase in fermentation intensity in the proposed BGP construction is achieved by the introduction of the nozzle 4, which creates a nutrient medium for the methane-forming bacteria by retaining portions of the heavy organic matter fraction on the side surfaces between the base of the nozzle 4, which is in the form of a multilayer mesh.

\section{Conclusions}

Based on the results of the studies and calculations, new scientifically substantiated theoretical results of solving an important scientific and technical problem of improving the efficiency of the functioning and structure of combined energy systems that realize the synergistic effects of uniting the possibilities of centralized and local energy in the field of application of alternative energy sources that are together necessary for the development of methods And means to improve the efficiency of fuel and energy use, as well as savings Energy in energy systems and complexes. Based on the results of scientific research, the following main results were obtained.

The proposed methodology allows to substantiate economic benchmarks for technological, organizational and technical measures in the construction and justification of the structure of energy supply systems using alternative sources and to obtain a predictable economic effect for the consumer from the implementation.

The principles of construction of combined power supply systems for agro-industrial complex consumers based on energy balances are presented and presented, which differ in the areas of extraction and processing of organic fuel in the form of an initial block diagram that allows to take into account changes in the technological processes for the preparation, production, transfer and distribution of all types of energy with loss accounting.

The scheme is improved and the efficiency of the technological process of energy supply to consumers of the agro-industrial complex is improved by increasing the output of commodity biogas up to 3 times, capable of long-term storage in gas cylinders with subsequent use at a time when it is necessary or useful for the consumer.

The heating system of BGP reactors has been improved by using an induction heater with a supply voltage of $0.38-0.22 \mathrm{kV}$, a frequency of $50 \mathrm{~Hz}$, which is installed on the surface of the object is heated, without contact with the heated liquid. It is shown that at the same time the design of the BGP reactor is simplified and the conditions for maintaining the temperature (mesophilic and thermophilic) operating modes are improved, carrying out its technical inspection and repair without stopping the technological process.

\section{References}

1. A. Goloskokov, Oil and Gas Business. 1, 1-13 (2010).

2. M. Brigida, Energy Economics. 43, 48-55 (2014).

3. M. Melichar, Energy Economics, 54, 431-443 (2016). 
4. M. Kurchchny, V. Fedoryko, V. Shcherban, Energy saving in agro-industrial complex (Textbooks and manuals, Ternopil, 2001).

5. P. Bajpai, V. Dash, Renewable \& Sustainable Energy Reviews, 16, 2926-2939 (2012).

6. Z. Glasnovic, J. Margeta, Renewable \& Sustainable Energy Reviews, 15, 1873-1884 (2011).

7. M. Irfan, J. Iqbal, A. Igbal, Z. Iqbal, R. Riaz, A. Mehmood, Renewable \& Sustainable Energy Reviews, 71, 652-674 (2017).

8. W. Liu, H. Lund, B. Mathiesen, X. Zhang, Applied Energy, 88, 518-525 (2011).

9. V. Marinakis, H. Doukas, P. Xidonas, C. Zopounidis, Omega-International Journal of Management Science. 69, 1-16 (2017).

10. M. Nehrir, C. Wang, K. Strunz, H. Aki, R. Ramakumar, J. Bing, Z. Miao, Z. Salameh, Alternative Energy Systems for Electric Power Generation: Configurations, Control, and Applications. 2, 392-403 (2017).

11. M. Pavlas, P. Stehlik, J. Oral, J. Sikula, Energy. 31, 2499-2511 (2006).

12. S. Dudnikov, Municipal economy of cities: energy-efficient appliances. 118, 67-71 (2014).

13. Ministry of Energy of Ukraine, GKD 340.000.001.95. The value of economic effectiveness of capital contributions to energy,(1995).

14. A. Purkus, E. Gawel, M. Deissenroth, K. Nienhaus, S. Wassermann, Energy Sustainability and Society. 5, (2015).

15. F. Ramirez, A. Honrubia-Escribano, E. Gomez-Lazaro, D. Pham, Energy Policy. 102, 440-452 (2017).

16. I. Trunova, O. Miroshnyk, O. Savchenko, International Conference on Intelligent Energy and Power Systems. 161-165 (2018).

17. M. Gonchar, S. Dudnikov, Patent UA 72106 (2005). 